\title{
A IMPOSSIBILIDADE DA UNIÃO ESTÁVEL DO DEFICIENTE MENTAL: UMA CRÍTICA AO ESTATUTO DA PESSOA COM DEFICIÊNCIA
}

\author{
THE IMPOSSIBILITY OF THE CIVIL UNION OF THE MENTAL \\ DEFICIENT: CRITICAL ESSAY ABOUT THE BYLAW OF PEOPLE WITH \\ DISABILITIES
}

1Bruna Kern Graziuso

\section{RESUMO}

A curatela sempre visou proteger a pessoa maior, padecente de alguma incapacidade ou de certa circunstância que impeça a sua livre e consciente manifestação de vontade. Diante da interdição, sendo o sujeito absolutamente incapaz, não poderia contrair matrimônio com outrem. O Estatuto da Pessoa com Deficiência (Lei 13.146/2015) introduziu diversas alterações no ordenamento jurídico. Os portadores de deficiência mental passam a ter plena capacidade, podendo inclusive casar e constituir união estável. Analisaremos a jurisprudência quanto aos conflitos de união estável e interdição antes da vigência do novo Estatuto, bem como discutiremos o direito da pessoa com deficiência de ter afeto.

Palavras-chave: Curatela, Interdição, União estável, Capacidade civil, Princípio da afetividade, Estatuto da pessoa com deficiência

\begin{abstract}
The curatorship institute was created to protect adults that, for some reason, are unable to express their will consciously. This mental deficient, after declared absolutely incapable, can' t get married. The legal community was surprise by the Bylaw of People with Disabilities, that changed the civil capacity institute. People with disabilities are now legally capable, being able to marry and live in civil union. We will analyze the jurisprudence of the legal cases about civil union between a capable person and a mental deficient before the new bylaw was created. Also, will discuss the right to affection of the mental deficient.
\end{abstract}

Keywords: Curatorship, Interdict, Civil capacity, Right to affection, Affection, Bylaw of people with disabilities 1 Mestranda em Direito no entro Universitário La Salle - Canoas, UNILASALLE, Rio Grande do Sul, RS. (Brasil).
Advogada. Email: bgraziuso@ gmail.com. 


\section{INTRODUÇÃO}

A curatela sempre foi instituto reservado aos sujeitos incapazes, absoluta ou relativamente, com exceção dos menores, para os quais o instituto aplicável ainda é a tutela. As hipóteses de incapacidade absoluta e relativa encontravam-se nos Arts. $3^{\circ} \mathrm{e}$ $4^{\mathrm{O}}$ do Código Civil Brasileiro, sendo os absolutamente incapazes: os menores de dezesseis anos; os que, por enfermidade ou deficiência mental, não tiverem o necessário discernimento para a prática dos atos da vida civil e os que, mesmo por causa transitória, não puderem exprimir sua vontade. Já os relativamente incapazes eram considerados: os maiores de dezesseis e menores de dezoito anos; os ébrios habituais, ou viciados em tóxicos, e os que, por deficiência mental, tenham o discernimento reduzido; os excepcionais, sem desenvolvimento mental completo e os pródigos.

O Estatuto da Pessoa com Deficiência (Lei 13.146/2015), que regulamentou a Convenção sobre os Direitos das Pessoas com Deficiência, tem gerado grandes debates entre civilistas, em decorrência de ter almejado a plena inclusão civil de pessoas que eram tidas como absolutamente e relativamente incapazes. Enquanto alguns juristas condenam as modificações por não resguardarem a vulnerabilidade de tais pessoas, outros aplaudem a inovação pela tutela de dignidade-liberdade das pessoas com deficiência. Independente da corrente defendida, inegável que a lei é polêmica e pouco desenvolvida, sem diferenciar os diferentes tipos e graus de deficiências mentais e sua influência na capacidade de discernimento do indivíduo.

O absolutamente incapaz, até então assim declarado por sentença de interdição, não possuía capacidade civil plena para contrair casamento. No que diz respeito a união estável, o Código Civil Brasileiro, ao contrário do que ocorre em relação ao casamento, não estabeleceu expressamente a capacidade como requisito essencial à constituição, dando margem assim a discussão de sua possibilidade na doutrina e jurisprudência, mesmo em momento anterior ao polêmico Estatuto da Pessoa com Deficiência.

Juntamente com a questão da possibilidade para o interditado viver em união estável, casos de relações afetivas entre pessoas civilmente capazes e deficientes mentais traz à tona questões sobre o princípio da afetividade no direito de família, sendo essas pessoas altamente vulneráveis, mas aptas de sentir amor e afeto. Contudo, 
a incapacidade também está relacionada com um baixíssimo grau de compreensão e discernimento dos atos praticados, sendo papel do Direito de Família lidar com essa linha tênue entre capacidade de sentir afeto e capacidade para viver em uma união estável reconhecida.

\section{OBJETIVO}

Analisar o instituto da interdição, através da curatela de pessoas absolutamente incapazes e a impossibilidade destas contrair união estável. Avaliar as inovações trazidas pela Lei 13.146/2015 quanto ao tema, bem como a posição da jurisprudência quanto ao tema. Examinar como os incapazes lidam com as relações humanas, dentro de suas limitações, e o direito dos mesmos de constituírem relações de afeto.

\section{METOLODOGIA}

Quanto ao objetivo da pesquisa, atribui-se método exploratório, haja vista que se busca aprimorar os conhecimentos, bem como construir hipóteses norteadoras no que diz respeito ao tema em apreço. O procedimento de pesquisa é bibliográfico, objetivando, de forma interdisciplinar, realizar a análise de referenciais teóricos já publicados.

\section{DESENVOLVIMENTO DA PESQUISA}

\subsection{CURATELA E EFEITOS DA INTERDIÇÃO ANTERIORES À LEI}

\section{$13.146 / 2015$}

Curatela, em sentido estrito, é o encargo cometido a alguém para dirigir a pessoa e administrar os bens de maiores incapazes que em virtude de doença, deficiência mental, vícios ou por outras causas duradouras, não podem exprimir sua vontade e cuidar dos próprios interesses, sendo, em regra, de caráter permanente (CARVALHO, 2015).

A curatela não se confunde com a tutela, que recai sobre os menores, presumidamente incapazes, constituindo medida de amparo e proteção aos maiores e 
emancipados, que se presume capazes e devem, por si mesmos, reger sua pessoa e administrar seus bens, encontrando-se, entretanto, privados de discernimento.

Tendo em vista a presunção de capacidade dos maiores ou emancipados, exige-se o pressuposto fático de incapacidade de fato do adulto, bem como o pressuposto jurídico de decisão judicial que declara que o maior é incapaz de reger sua pessoa e administrar os seus bens, ou apenas administrar o patrimônio, no caso do pródigo, interditando-se e nomeando curador.

Os sujeitos a curatela estão elencados no Art. 1.767 do Código Civil Brasileiro, enquanto os legitimados para propor ação de interdição estão elencados no Art. 1.768, $\mathrm{CC}^{1}$. A sentença de interdição é declaratória, pois reconhece uma situação fática já existente. Maria Helena Diniz ${ }^{2}$ acolhe o entendimento de que a sentença é declaratória e constitutiva, sob o fundamento de que, em regra, só depois de decretada a interdição é que se recusa a capacidade de exercício, sendo nulo ou anulável o ato praticado, conforme seja o interditado, considerado absoluto ou relativamente incapaz, produzindo, portanto, efeitos ex nunc, embora seja possível invalidar ato praticado por doente mental, mesmo antes da decretação judicial de sua interdição, desde que se comprove judicialmente a existência de sua insanidade por ocasião da efetivação do ato negocial.

A interdição pode ser promovida pelo cônjuge ou companheiro; pelos parentes ou tutores; pelo representante da entidade em que se encontra abrigado o interditando ou pelo Ministério Público, legitimidade que deverá ser comprovada por documentação que acompanhe a petição inicial, em concordância com a nova redação do Art. 747, do Novo Código de Processo Civil Brasileiro de 2015, que revogou os Arts. 1.768 a 1773, CC/02, que até então tratavam sobre a promoção da interdição (LÔBO, 2015).

1 Art. 1.767. Estão sujeitos a curatela:

I - aqueles que, por enfermidade ou deficiência mental, não tiverem o necessário discernimento para I - aqueles que, por enfermidade ou deficiência mental, não tiverem o necessário discernimento para os atos da vida civil;

II - aqueles que, por outra causa duradoura, não puderem exprimir a sua vontade;

III - os deficientes mentais, os ébrios habituais e os viciados em tóxicos;

$I V$ - os excepcionais sem completo desenvolvimento mental;

$V$ - os pródigos.

Art. 1.768. A interdição deve ser promovida:

I - pelos pais ou tutores;

II - pelo cônjuge, ou por qualquer parente;

III - pelo Ministério Público.

2 DINIZ, Maria Helena. Curso de direito civil brasileiro: Direito de família. p. 616. 
Decretada a interdição, o juiz nomeará curador e fixará os limites da curatela, segundo o estado e o desenvolvimento do interdito, considerando as características pessoais deste, observando suas potencialidades, habilidades, vontades e preferências, de acordo com o Art. 755, do NCPC/2015. Importante inovação trazida pelo NCPC/2015 está no Art. 758, que salienta a necessidade do curador buscar tratamento e apoio apropriados à conquista e autonomia do interdito.

\subsection{A UNIÃO ESTÁVEL E A INCAPACIDADE}

A questão da incapacidade e união estável merece destaque quando a última surge em momento posterior a interdição. Pode o incapaz conviver em vínculo de união estável?

O tema foi objeto de discussão no REsp 1.201.462-MG ${ }^{3}$, julgado em 14.04.2011, de relatoria do Ministro Massami Uyeda. A recorrente buscava o reconhecimento da união estável, mas à época do relacionamento, seu companheiro estava acometido de insanidade mental. Dois posicionamentos foram apresentados, um defendendo que impedir a união estável na espécie seria contrária a Constituição Federal, Art. 226, $\S 3^{\circ}$, que determina que o Estado proteja a união estável como entidade familiar e facilite sua conversão em casamento. Contudo, a tese vencedora explicou que, se o enfermo mental não tem o necessário discernimento para os atos da

${ }^{3}$ RECURSO ESPECIAL - AÇAO DECLARATÓRIA DE RECONHECIMENTO DE UNIÃO ESTÁVEL - NEGATIVA DE PRESTAÇAO JURISDICIONAL - NAO-OCORRÊNCIA ALTERAÇAO DA BASE FÁTICA SOB A QUAL SE FUNDOU O ARESTO A QUO IMPOSSIBILIDADE NESTA INSTÂNCIA ESPECIAL - INTELIGÊNCIA DA SÚMULA N. 7/STJ PRETENSO COMPANHEIRO DESPROVIDO DO NECESSÁRIO DISCERNIMENTO PARA A PRÁTICA DOS ATOS DA VIDA CIVIL - IMPOSSIBILIDADE DO RECONHECIMENTO DA RELAÇAO PRETENDIDA (UNIÃO ESTÁVEL) - RECURSO ESPECIAL A QUE SE NEGA PROVIMENTO.

1. Não existe negativa de prestação jurisdicional no acórdão que, a despeito de adotar fundamento diverso daquele pretendido pela parte, efetivamente decide de forma fundamentada toda a controvérsia, como sucede in casu.

2. O recurso especial presta-se a definir a interpretação da lei federal e não a rediscutir a base fática sobre a qual se fundou o acórdão recorrido.

3. Se o "enfermo mental sem o necessário discernimento para os atos da vida civil" (artigo 1.548, inciso I, do Código Civil) não pode contrair núpcias, sob pena de nulidade, pela mesma razão não poderá conviver em união estável, a qual, neste caso, jamais será convertida em casamento. A adoção de entendimento diverso, data venia , contrariariao próprio espírito da Constituição Federal, a qual foi expressa ao determinar a facilitação da transmutação da união estável em casamento.

4. A lei civil exige, como requisito da validade tanto dos negócios jurídicos, quanto dos atos jurídicos no que couber -, a capacidade civil (artigo 104, 166 e 185, todos do Código Civil).

5. Não só pela impossibilidade de constatar-se o intuito de constituir família, mas também sob a perspectiva das obrigações que naturalmente emergem da convivência em união estável, tem-se que o incapaz, sem o necessário discernimento para os atos da vida civil, não pode conviver sob tal vínculo.

6. Recurso especial desprovido. 
vida civil, também não poderia contrair núpcias sob pena de nulidade e, pela mesma razão, não poderia conviver em união estável.

O Ministro ainda lembrou que a convivência também gera efeitos patrimoniais, $\log$ o não seria só pela impossibilidade de constatar o intuito de constituir família, mas também porque a convivência em união estável geraria obrigações ao incapaz, sem o necessário discernimento para os atos da vida civil, conviver sob o vínculo de união estável.

Em verdade o Art. 226, $\$ 3^{\circ}$ determina que o Estado proteja a união estável enquanto entidade familiar, devendo, pois, facilitar sua conversão em casamento, atribuindo especial proteção à família, inclusive aquela não respaldada no matrimônio, a antever sua elevada importância na busca pela preservação e promoção da dignidade da pessoa humana. Daí decorre, portanto, que a tutela do núcleo familiar não é um fim em si mesmo, senão um instrumento de salvaguarda dos membros que a compõem.

Na linha desse raciocínio, o Código Civil Brasileiro de 2002 estabeleceu, em seu artigo 1.723, que: “é reconhecida como entidade familiar a união estável entre homem e a mulher, configurada na convivência pública, contínua, duradoura e constitutiva de família". Todavia, não basta, para a caracterização da união estável, a presença dos requisitos do Art. 1.723, CC, porquanto a própria lei estabelece, de igual modo, como pressuposto para o reconhecimento do vínculo, requisitos negativos, cuja verificação tem o condão de impedir a formação da união estável. De efeito, o parágrafo primeiro do artigo citado dispõe: “a união estável não se constituirá se ocorrerem os impedimentos do Art. $1.521^{4}$, não se aplicando a incidência do inciso VI no caso de a pessoa casada se achar separada de fato ou judicialmente". O STJ, ao analisar os requisitos necessários à configuração da união estável no REsp 1.157.273/RN, de relatoria da Ministra Nancy Andrighi em 07/06/2010, incluiu a ausência de impedimentos para o casamento como requisito essencial.

${ }^{4}$ Art. 1.521. Não podem casar:

I - os ascendentes com os descendentes, seja o parentesco natural ou civil;

II - os afins em linha reta;

III - o adotante com quem foi cônjuge do adotado e o adotado com quem o foi do adotante;

IV - os irmãos, unilaterais ou bilaterais, e demais colaterais, até o terceiro grau inclusive;

$V$ - o adotado com o filho do adotante;

$V I$ - as pessoas casadas;

VII - o cônjuge sobrevivente com o condenado por homicídio ou tentativa de homicídio contra o seu consorte. 
A par de tais considerações, verifica-se que a Lei Civil, ao contrário do que ocorre em relação ao casamento, não estabelece expressamente, no titulo do Direito de Família, a capacidade como requisito essencial à sua constituição. De efeito, o Art. 1.548, I, CC, prevê a nulidade do casamento contraído "pelo enfermo mental sem o necessário discernimento para os atos da vida civil". Assim, o entendimento amplamente majoritário, tanto da doutrina quanto da jurisprudência, consiste em não se reconhecer a união estável quando inviável juridicamente o casamento. Tanto é que o Art. 1.727, CC, prevê que "as relações não eventuais entre o homem e a mulher impedidos de casar constituem concubinato", e não união estável.

Logo, se a união estável é dotada de proteção estatal, inclusive quanto à necessidade de se facilitar a sua conversão em casamento, tem-se que o referido vínculo deve ser compreendido como sendo a convivência pública, duradoura, contínua entre duas pessoas vivendo ou não sob o mesmo teto, que cultivam o intuito de constituir família, desde que, por ausência de impedimentos, possam contrair matrimônio. Se o enfermo mental sem o necessário discernimento para os atos da vida civil não pode contrair núpcias, sob pena de nulidade, pela mesma razão não poderá conviver em união estável, a qual, neste caso, jamais poderá ser convertida em casamento. A adoção de entendimento diverso, de acordo com o já citado REsp 1.201.462-MG, contraria o próprio espírito da Constituição Federal, a qual foi expressa ao determinar a facilitação da transmutação da união estável em casamento.

De mais, em seu voto no acórdão ora analisado, o Ministro Massami Uyeda explica que Lei Civil exige, como requisito da validade tanto dos negócios jurídicos quanto dos atos jurídicos, no que couber, a capacidade civil (Arts. 104 e 166 c/c Art. 185, CC). Portanto, quer se considere a união estável um negócio jurídico, quer um ato jurídico, a higidez mental é requisito essencial ao seu reconhecimento.

Importante ainda ressaltar o intuito familae, objetivo de constituir família necessário para caracterizar a união estável, que é este elemento subjetivo, dizendo respeito à intenção do casal de estar vivendo como se casados fossem (FARIAS \& ROSENVALD, 2011). Ocorre que, diante de um estado de perturbação psíquica da qual qualquer ser humano pode, em razão das mais diversas razões da vida, se ver acometido, não há como considerar ou aferir a presença do animus familae.

Os atos da vida civil pressupõem, para sua validade, que o agente que venha a praticá-los tenha capacidade para tanto. Assim, não deve ser diferente para a configuração da união estável. Esta exige que o agente manifeste, ainda que de forma 
tácita, vontade de convivência pública, contínua e duradoura com outra pessoa, com intenção de constituir uma família. Se o agente não tem capacidade para tanto, visto ser portador de enfermidade mental, não há como se admitir a vontade para a existência de uma união estável em que ele seja parte (FARIAS \& ROSENVALD, 2011).

Ademais, a convivência produz efeitos patrimoniais entre os companheiros, do quanto dispõe o Art. 1.725, CC: "na união estável, salvo contrato escrito entre os companheiros, aplica-se às relações patrimoniais, no que couber, o regime da comunhão parcial de bens". Ressalta-se, outrossim, que, sem a capacidade civil, estariam estes conviventes impedidos até mesmo de, por contrato, firmar regime patrimonial de bens diverso da comunhão parcial.

Assim, não só pela impossibilidade de constatar-se o intuito de constituir família, mas também sob a perspectiva das obrigações que naturalmente emergem da convivência em união estável, tem-se que o incapaz, sem o necessário discernimento para os atos da vida civil, não pode conviver sob tal vínculo.

\subsection{O ESTATUTO DA PESSOA COM DEFICIÊNCIA (LEI 14.146/2015)}

O Estatuto da Pessoa com Deficiência foi recebido com perplexidade pela comunidade jurídica em 06 de julho de 2015, entrando em vigor em 03 de janeiro de 2016. A mais profunda mudança concentra-se nos Arts. $3^{\circ}$ e $4^{\circ}$ do CC/02. O Art. $3^{\circ}$ definia os absolutamente incapazes, como já visto, como menores de 16 anos; os que, por enfermidade ou deficiência mental, não tivessem o necessário discernimento para praticar seus atos e, por fim, os que, mesmo por causa transitória, não pudessem exprimir sua vontade. A Lei 13.146/2015 revogou todos os incisos, exceto o primeiro, referente aos menores de $16 \operatorname{anos}^{5}$.

\footnotetext{
${ }^{5}$ Art. 114. A Lei 10.406 de 10 de janeiro de 2002 (Código Civil), passa a vigorar com as seguintes alterações: "Art. $3^{\circ}$ : São absolutamente incapazes de exercer pessoalmente os atos da vida civil os menores de 16 (dezesseis) anos."

I - (Revogado);

II - (Revogado);

III - (Revogado).” (NR)
} 
O Art. $4^{\circ}$, que trata dos relativamente incapazes, definia como tais os maiores de 16 e menores de 18 anos; ébrios habituais, viciados em tóxicos e os que, por deficiência mental, tenham o discernimento reduzido; os excepcionais, sem desenvolvimento mental completo e os pródigos. Pela nova redação, restou como relativamente incapazes apenas os ébrios habituais, viciados em tóxicos e aqueles que, por causa transitória ou permanente, não puderem exprimir sua vontade ${ }^{6}$. Com isso, os portadores de deficiência mental passam a ter plena capacidade, podendo inclusive casar e constituir união estável, entre outros direitos expressamente elencados no Art. $6^{\circ}$ da Lei $13.146 / 2015^{7}$.

Porém, a Lei 13.146/2015 não surgiu como algo tão inesperado. No ano de 2009, houve o advento a Convenção sobre os Direitos das Pessoas com Deficiência, incorporada ao direito interno brasileiro por meio do Decreto Legislativo 186/2008 e por sua promulgação pelo Decreto Executivo 6.949/2009. A Lei 13.146/2015, portanto, surgiu para regulamentar a Convenção. Assim, desde o ano de 2009, a pessoa com deficiência não mais se inclui entre os absolutamente incapazes de exercício de direitos (LÔBO, 2015).

A referida lei ressalva que, em situações excepcionais, a pessoa com deficiência mental ou intelectual poderá ser submetida a curatela, no seu interesse

${ }^{6}$ Art. $4^{\mathrm{o}}$ : "São incapazes, relativamente a certos atos ou à maneira de os exercer:

II - os ébrios habituais e os viciados em tóxico;

III - aqueles que, por causa transitória ou permanente, não puderem exprimir sua vontade;

${ }^{7}$ Art. $6^{o}$ A deficiência não afeta a plena capacidade civil da pessoa, inclusive para:

I - casar-se e constituir união estável;

II - exercer direitos sexuais e reprodutivos;

III - exercer o direito de decidir sobre o número de filhos e de ter acesso a informações adequadas sobre reprodução e planejamento familiar;

IV - conservar sua fertilidade, sendo vedada a esterilização compulsória;

$V$ - exercer o direito à família e à convivência familiar e comunitária; e

VI - exercer o direito à guarda, à tutela, à curatela e à adoção, como adotante ou adotando, em igualdade de oportunidades com as demais pessoas. 
exclusivo e não de parentes e/ou terceiros. Essa curatela, ao contrário do instituto da interdição anterior, deve ser feita em concordância com o Art. 84 da nova lei ${ }^{8}$, sendo esta proporcional às necessidades e circunstâncias de cada caso e "durará o menor tempo possível", tendo natureza protetiva e não mais de interdição de exercício de direitos. Essa específica curatela afetará apenas negócios jurídicos relacionados aos direitos de natureza patrimonial (LÔBO, 2015).

O Estatuto da Pessoa com Deficiência ignora por completo o sistema da capacidade de fato, centrado na ideia de cognoscibilidade e autodeterminação, sendo plenamente capaz para os atos da vida civil aquele que compreende e se autodetermina e que, portanto, tem pleno poder de gerenciar sua vida, seus negócios e seus bens. $\mathrm{O}$ discernimento é a base desse instituto. Aquele que não compreende e nem se autodetermina precisa ser rigorosamente protegido, função esta que era desempenhada pelos Arts. $3^{\circ}$ e $4^{\circ}$ do Código Civil Brasileiro. A vulnerabilidade do indivíduo jamais deveria ser desconsiderada pelo ordenamento, e é exatamente isto que a Lei 13.146/2015 faz (KUMPEL \& BORGARELLI, 2015).

Como anteriormente mencionado, o novo CPC revogou os Arts. 1.768 a 1.773, CC, que tratavam da promoção da curatela, aparentemente por disciplinarem assuntos de direito processual e não material. O NCPC desconsiderou tanto o Estatuto da Pessoa com Deficiência como a Convenção sobre os Direitos das Pessoas com Deficiência, que tem força de emenda constitucional, por ser matéria de direitos humanos, com supremacia sobre qualquer lei ordinária (LÔBO, 2015). Inclusive, os Arts. 747 e seguintes do NCPC tratam sobre o instituto da interdição 9 .

\footnotetext{
${ }^{8}$ Art. 84. A pessoa com deficiência tem assegurado o direito ao exercício de sua capacidade legal em igualdade de condições com as demais pessoas.

$\S 1^{\underline{o}}$ Quando necessário, a pessoa com deficiência será submetida à curatela, conforme a lei.

$\S 2^{o}$ É facultado à pessoa com deficiência a adoção de processo de tomada de decisão apoiada.

$\S 3^{o}$ A definição de curatela de pessoa com deficiência constitui medida protetiva extraordinária, proporcional às necessidades e às circunstâncias de cada caso, e durará o menor tempo possível.

$\S 4^{-}$Os curadores são obrigados a prestar, anualmente, contas de sua administração ao juiz, apresentando o balanço do respectivo ano.

${ }^{9}$ Art. 747. A interdição pode ser promovida:
} 
Com a vigência do Estatuto, tais pessoas ficam abandonadas à própria sorte, sendo dramática a situação imposta a grupo de indivíduos que tanto precisam de proteção. Ao nivelar todos os tipos de deficiências mentais, o legislador ignora o fato de existirem diferentes níveis de incapacidade intelectual, sendo alguns casos extremamente graves, estando o indivíduo absolutamente inabilitado para compreender e discernir qualquer ato da vida civil. Essa situação fica ainda mais evidente na análise da jurisprudência a seguir, em casos de tentativa de reconhecimento de união estável entre uma pessoa capaz e um interditado.

\subsection{O PRINCÍPIO DA AFETIVIDADE E AS PESSOAS COM DEFICIÊNCIA}

Todo o moderno Direito de Família gira em torno do princípio da afetividade, onde o próprio conceito de família nasce. A comunidade de existência formada pelos membros de uma família é moldada pelo liame socioafetivo que os vincula, sem aniquilar as suas individualidades (GAGLIANO \& PAMPLONA FILHO, 2013). Apesar da definição de que a afetividade como um princípio não seja unânime, não é possível pensar na entidade familiar sem a presença de afeto, uma vez que as relações que se desenvolvem no seio da família estão embasadas em amor, cuidados, carinho e respeito (ROSA, 2013).

Um caso em particular trouxe à tona a discussão sobre as relações de afeto de incapazes, em que o STJ não reconheceu a união estável alegada por cuidadora de um paciente de esquizofrenia grave $\mathrm{e}^{10}$. No caso, a cuidadora foi contratada para prestar auxílio a rapaz portador de esquizofrenia grave, alegando posteriormente que o convívio transformou-se em amor. Em primeira instância, a ação foi julgada

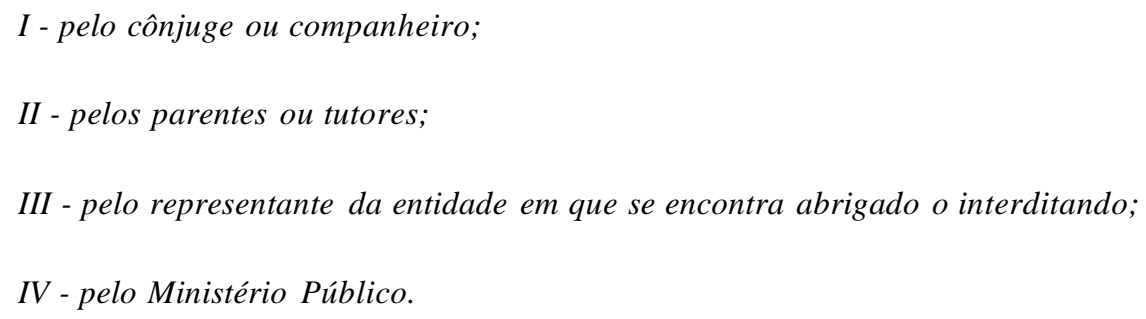

${ }^{10}$ Em concordância com informações do próprio STJ, o número deste processo não é divulgado em razão de sigilo judicial. 
improcedente, tendo o Tribunal de Justiça do Rio Grande do Sul (TJRS) reformado a decisão com base em depoimento do psiquiatra de longa data do incapaz. Segundo o TJRS, o médico foi taxativo ao afirmar que o paciente não era capaz de gerir sua vida financeira, porém tinha discernimento para entender as relações conjugais e firmar laços afetivos.

Já no entendimento do Ministro Marco Aurélio Bellizze, relator do recurso no STJ, restou comprovado que o rapaz, com idade mental comparável à de uma criança de sete anos, possui limitações de juízo crítico e responsabilidade civil, não tendo capacidade para tomar decisões de cunho patrimonial ou assumir responsabilidades financeiras: "Encontrando-se o indivíduo absolutamente inabilitado para compreender e discernir os atos da vida civil, também estará, necessariamente, para vivenciar e entender, em toda a sua extensão, uma relação marital, cujo propósito de constituir família, por tal razão, não pode ser manifestado de modo voluntário e consciente", nas palavras do relator ${ }^{11}$.

Afinal, quais os limites do afeto e capacidade de discernimento do interditado? De acordo com a psicanalista Giselle Groeninga, diretora de Relações Interdisciplinares do IBDFAM, o transtorno do rapaz implica um alto grau de vulnerabilidade e, assim, de necessidade de cuidado e compreensão. O interditado tem direito à realização afetiva na medida de sua capacidade, discernimento e responsabilidade. Como a referida profissional ensina, devem ser contemplados níveis de incapacidade, vulnerabilidade e interdição. Dentro das suas limitações, essas pessoas ainda necessitam realizar seus direitos de personalidade, com ênfase no direito a afetividade (GROENINGA, 2006).

Nas situações que envolvem afetividade, não há que se falar em representação, mas em responsabilidade pelo cuidado com o deficiente mental. De uma forma geral, o afeto é expressado de forma ainda mais intensa por este, em decorrência da sua imaturidade, devendo a pessoa que recebe o afeto deste ter ainda mais responsabilidade e cuidado, em um espaço de desenvolvimento mental precário, onde impulsos e sentimentos se confundem.

A chave das relações de afeto da pessoa com deficiência está em não negar sua realização, mas pensar em suas formas possíveis, não privá-los completamente de

${ }^{11}$ IBDFAM. Caso de cuidadora que alegou união estável com incapaz traz à tona reflexes sobre afeto $e$ sexualidade . Disponível em: http://www.ibdfam.org.br/noticias/5563 . Acesso em: 04/07/2015. 
suas realizações afetivas, dentro de suas limitações, respeitando sua dignidade e permitindo desenvolver afetividade.

Como ensina Sérgio Rezende de Barros:

"O afeto é, primariamente, uma relação entre indivíduos que se afeiçoam. Logo, a Constituição o protege como direito individual: direito humano de qualquer indivíduo. Nessa dimensão individual, o direito ao afeto é a liberdade de afeiçoar-se um a outro. É uma liberdade constitucional." (BARROS, 2006)

O direito da pessoa com deficiência ao afeto, portanto, vai além de sua incapacidade para contrair casamento e viver em união estável. Apesar de suas limitações, sabemos que este pode vir a ter relações afetivas, dando sentido e dignidade à sua existência como ser humano, mesmo com grau de compreensão prejudicado, respeitando seus limites de discernimento e com responsabilidade, principalmente da pessoa objeto deste afeto.

\section{CONSIDERAÇÕES FINAIS}

Os sujeitos a curatela estão elencados no Art. 1.767, CC, podendo ser absoluta ou relativamente incapazes, conforme definirá a sentença declaratória de interdição, após perícia

médica, concluindo o juiz pelo reconhecimento da incapacidade do indivíduo. Tratase de um instituto que visa proteger os interesses do curatelado ou interdito, com ênfase, porém não exclusivamente, de caráter patrimonial.

Como até então sujeitos incapazes de exercerem pessoalmente os atos da vida civil, não podiam contrair matrimônio nem viver em união estável. Tudo mudou com o surgimento da Lei 13.146/2015, chamada de Estatuto da Pessoa com Deficiência, que revogou os Arts. $3^{\circ}$ e $4^{\circ}$ do Código Civil Brasileiro, tornando as pessoas com deficiência mental civilmente capazes e passíveis de contrair matrimônio e viver em união estável. As críticas a nova lei são inúmeras, principalmente o fato de não diferenciarem graus e tipos de enfermidades mentais, tornando todas pessoas com deficiência plenamente capazes, independente de ter discernimento para tanto.

Por sua vez, o Novo Código de Processo Civil ignorou as novas regras impostas pelo Estatuto, regulando o instituto da interdição em seus Arts. 747 a 758. Além de não considerar a Lei 13.146/2015, lei ordinária, não obedeceu o estabelecido 
na Convenção sobre os Direitos das Pessoas com Deficiência, com status de emenda constitucional.

A discussão restou apenas quanto a possibilidade de reconhecimento de união estável entre interditado e pessoa capaz antes da vigência da Lei 13.146/2015, possibilidade esta amplamente negada na jurisprudência. Não tendo como o incapaz manifestar sua vontade de constituir família, diante de sua enfermidade mental, não está presente o animus familae, um dos elementos necessários para caracterizar a união estável.

Independente da discussão sobre a capacidade civil, as pessoas com deficiência possuem o direito de receber e transmitir afeto, baseado em relações que requerem ainda mais responsabilidade e cuidado, em decorrência de um desenvolvimento mental e intelectual imaturo. Assim, o principal objetivo de garantir o direito a afetividade dessas pessoas está em não negá-las a plena realização de suas personalidades, respeitando o princípio da dignidade da pessoa humana. Ganhando o afeto valor jurídico, os direitos das pessoas incapazes de praticar negócios e atos jurídicos passou a ser valorizado, permitindo o desenvolvimento da afetividade dentro de suas limitações.

\section{REFERÊNCIAS}

BARROS, Sérgio Rezende de. A tutela constitucional do afeto. PEREIRA, Rodrigo da Cunha (coord). Família e dignidade humana. Anais do V Congresso Brasileiro de Direito de Família. Belo Horizonte. IBDFAM, 2006.

CARVAlHO, Dimas Messias de. Direito das Famílias. Belo Horizonte: Saraiva, 2015.

DIAS, Maria Berenice. Manual do Direito das Famílias. Porto Alegre: Livraria do Advogado, 2005.

DINIZ, Maria Helena. Curso de Direito Civil: Direito de Família. São Paulo: Saraiva, 2000.

FARIAS, Cristiano Chaves de; ROSENVALD, Nelson. Direito das Famílias. Rio de Janeiro: Lumen Juris, 2011. 
GAGLIANO, Pablo Stolze; PAMPLONA FILHO, Rodolfo. Novo Curso de Direito

Civil: Direito de Família. São Paulo: Saraiva, 2013.

GROENINGA, Giselle Câmara. O direito à integridade psíquica e o livre desenvolvimento da personalidade. In: PEREIRA, Rodrigo da Cunha (coord). Família e dignidade humana. Anais do V Congresso Brasileiro de Direito de Família. Belo Horizonte. IBDFAM, 2006.

GOMES, Luiz Flávio. O incapaz pode conviver sob o vínculo da união estável: Disponível em: http://professorlfg.jusbrasil.com.br/artigos/121922207/o-incapaz-podeconviver-sob-vinculo-de-uniao-estavel Acesso em: 04.07.2015

GONÇALVES, Carlos Roberto. Direito Civil Brasileiro - Direito de Família. São Paulo: Saraiva, 2015.

IBDFAM. Caso de cuidadora que alegou união estável com incapaz traz à tona reflexos sobre afeto e sexualidade. Disponível em: http://www.ibdfam.org.br/noticias/5563 Acesso em: 04.07.2015.

KUMPEL \& BORGARELLI. As aberrações da Lei 13.146/2015. Disponível em: http://www.migalhas.com.br/dePeso/16,MI224905,61044As+aberracoes+da+lei+131462015 Acesso em: 03.04.2016.

LÔBO, Paulo. Com avanços legais, pessoas com deficiência mental não são mais incapazes. Disponível em: http://www.conjur.com.br/2015-ago-16/processo-familiaravancos-pessoas-deficiencia-mental-nao-sao-incapazes Acesso em: 03.04.2016

ROSA, Conrado Paulino de. iFamily: Um novo conceito de família? São Paulo: Saraiva, 2013. 